\title{
Ensino Agrícola no Estado de São Paulo: Introdução ao Estudo da Relação Trabalho-Educação
}

Pesquisadora: Lourdes Marcelino Machado

Instituição: Universidade Estadual Paulista (UNESP/Marilia)

Fonte Financiadora: Instituto Nacional de Estudos e Pesquisas Educacionais (INEP)

As questões norteadoras do estudo tiveram sua origem remota em minha experiência como diretora da escola agrícola quando, ao assumir a direção da escola, tive como primeira constatação a de que o aspecto substantivo (ensino) estava subjugado pelo adjetivo (agrícola). Os problemas emergentes, sempre urgentes, ligados aos aspectos materiais e financeiros e de manutenção do internato, sufocam as questões de ensino propriamente dito. Daí vieram minhas primeiras questões:

Existem pontos comuns entre o ensino agrícola e os demais ramos de ensino? $O$ que torna o ensino agrícola tão específico? Sua natureza ou sua historicidade? Os problemas crônicos do ensino agrícola são decorrência de sua natureza? São agravados em função de sua especificidade ou da tentativa de fazê-lo semelhante às outras modalidades de ensino? Se na representação de seus agentes, as especificidades são dominantes, como isso se reflete na ação docente? É possível ao ensino agrícola, tal como foi estruturado, superar a dicotomia educação geral $\mathrm{x}$ formação especial? Teoria $\mathrm{x}$ prática? Ensino X produção?

Os pressupostos que orientaram a pesquisa foram: 
1. A perspectiva histórica é elemento fundamental para a compreensão do presente e para divisar alternativas sobre o futuro. Portanto, a natureza das questões referentes ao ensino agrícola podem ser melhor compreendidas se tomadas nessa perspectiva.

2. O ensino agrícola padece dos mesmos males que a educação em geral e $\mathrm{cm}$ decorrência de sua especificidades os problemas são agudizados, tornando-se crônicos.

3. O ensino agrícola não tem sido objeto de muitos estudos e quando o é, sempre o é sem incorporar os avanços obtidos pelos estudiosos da educação.

Através da pesquisa de campo, busquei colher informações adicionais às obtidas na literatura disponível e captar o significado que os agentes educacionais atribuem às questões levantadas. Sob essa perspectiva, procurei contrapor e reunir duas instâncias do pensamento e da ação educacionais referentes ao ensino agrícola: o dos órgãos centrais e o da unidade escolar. Assim, aos dados coletados através da pesquisa bibliográfica e à frieza dos documentos legais, pude contrapor as informações da memória viva dos que estiveram envolvidos nas ações governamentais.

No primeiro capítulo, apresento um recorte histórico da evolução do ensino agrícola no Estado de São Paulo, onde identifico momentos cruciais ligados à gestão do sistema. Tais momentos referem-se, em especial, às mudanças nos órgãos gestores do ensino agrícola. O trabalho tem como marco temporal final o ano de 1991, quando uma nova fase do desenvolvimento do ensino agrícola se inicia com a instituição de um novo gestor: a Secretaria de Ciência e Tecnologia.

No capítulo segundo, discuto a organização e o funcionamento do ensino agrícola sob a ótica da incorporação do trabalho agrícola às propostas pedagógicas das escolas. Procuro demonstrar como o trabalho agrícola assume posição nuclear nas propostas pedagógicas, destacando o reducionismo contido nas diferentes concepções. Tal reducionismo converte a relação trabalho-educação sob o ponto de vista do ensino-produção. 
A análise privilegia três momentos: o Sistema Escola-Fazenda; o Modelo de Projetos Agropecuários e a recente proposta de Reorganização Curricular. Como horizonte, situa a questão do ensino técnico no Projeto da nova LDB e na Reforma Fleury.

Quero frisar a legitimidade e a necessidade de se abordar a questão educação-trabalho em relação ao ensino agrícola pela escassez de estudos dessa natureza. Embora o tema da relação trabalhoeducação venha sendo objeto de muita discussão, ele é freqüentemente analisado do ponto de vista da fábrica, como se a sociedade industrial exercesse um estranho e poderoso fascínio sobre os pensadores sociais, fazendo com que outros setores do mundo do trabalho fiquem obscurecidos e intocados.

No Sistema Escola-Fazenda, o objetivo era o de formação do agricultor independente, Polivalente, e essa foi a espinha dorsal da organização e funcionamento do modelo. Contudo, a complexidade com que foi idealizada a Cooperativa Escolar, elemento-chave do sistema, sua estrutura burocrática, condizente com a tendência tecnoburocrata predominante à época, foi um dos elementos responsáveis pelo seu fracasso.

O Modelo de Projetos Agropecuários apresenta-se como uma proposta metodológica calcada no Método de Projetos. Há forte influência de Dewey, em especial através de Kilpatrick, o que é expresso no próprio manual. Porém, à primeira vista, parece-nos que essa influência se dá de modo estreito, como um receituário. É o que se deduz a partir do texto de apresentação do material, segundo o qual o "Manual resume um roteiro básico das atividades agropecuárias, que deve se constituir em instrumento indispensável ao ensino" (p.17).

O manual não dá atenção aos aspectos fundamentais da relação educação-trabalho, reduzindo-a aos aspectos técnicos de como elaborar os projetos. A simples leitura comparativa das intruções contidas no "Manual Escola-Fazenda", especificamente nos itens de "Laboratório de Prática e Produção" (LPP) e "Programa Agrícola Orientado" (PAO) e das contidas no 
"Manual de Projetos Agropecuários", evidencia uma enorme semelhança entre ambas as orientações. Essa semelhança se traduz nas fórmulas matemáticas, instruções e modelos a serem utilizados no planejamento das atividades práticas.

Dessa forma, entre o Sistema Escola-Fazenda e o Modelo de Projetos Agropecuários parece existir muito mais continuidade do que ruptura. A meu ver, a ruptura deu-se em função do órgão gestor da rede e do colapso das cooperativas escolares. A continuidade fica traduzida nos demais elementos de permanência: fazenda, internato $\mathrm{c}$ composição curricular, onde o LPP e o PAO do sistema anterior, agrupam-se no PP (Prática de Projetos) do modelo novo.

Sob a gestão da Divisão de Supervisão e Apoio às Escolas Técnicas Estaduais (DISAETE), em 1989, encaminha-se às unidades escolares, para análise e discussão, uma proposta de reorganização curricular, com o objetivo de "melhoria da qualidade do ensino" da habilitação profissional plena de Agropecuária (GD/DISAETE, Ofício Circular $n^{\circ}$ 69/89).
A análise dessa proposta permite supor uma concepção fragmentada do processo educativo nas escolas agrícolas. A organização da escola em quatro setores de atividade - Teoria, Prática, Prática de Projetos, Aplicação - sugere uma reaproximação das quatro áreas do Sistema Escola-Fazenda. A meu ver, o paralelismo entre as áreas propostas pelo Sistema Escola-Fazenda e os setores de atividades da propsta atual salta logo à primeira vista. Contudo, enquanto no primeiro se enfatiza o vínculo trabalho-educação (ou de modo mais restrito produção-ensino), na segunda proposta se acentua o desvinculo.

De tudo isso, depreende-se a grande dificuldade de concepção acerca da forma pela qual o trabalho deva ser incorporado à organização das escolas agrícolas, os argumentos não são suficientes, talvez por faltar a devida clareza sobre os fundamentos da relação trabalhoeducação no cotidiano da escola.

Mesmo no atual Programa de Reforma do Ensino Público Paulista (1991), quando as escolas técnicas são transferidas da Secretaria da 
Educação para a Secretaria de Ciência e Tecnologia, o ensino tecnico não parece ter sido adequadamente tratado, pois a questão não se resume à definição de quai órgão é adequado para exercer a gestão das escolas que ministram o ensino técnico. Trata-se, isto sim, de rediscutir as bases possíveis de organização desse ensino à luz de uma concepção clara de ensino médio c profissional, para então construir sua identidade. A questão do ensino médio como um todo pennanece. E permanece como um desafio conceitual, metodológico e político. A expansão do ensino médio, enquanto educação básica $\mathrm{c}$, portanto, comum a todos, é um grande desafio político. Enquanto que a "identidade", os conteúdos, a relação teoria x prática, o trabalho como princípio educativo, entre outros, são imensos desafios conceituais e metodológicos, que por sua vez só podem ser enfrentados mediante uma filosofia de educação consistente que fundamenta a política educacional.

No terceiro capítulo, faço uma síntese das entrevistas realizadas com agentes educacionais que representam duas instâncias do sistema: os órgãos centrais e a unidade escolar. Chamo de gestores aos agentes que, como integrantes dos órgãos centrais, detêm o poder de formular a política educacional consubstanciada em normas e diretrizes. Chamo de operadores aos agentes educacionais que atuam na base do sistema, responsáveis pela execução das diretrizes e normas definidas pelos gestores, $\mathrm{cm}$ nivel de unidade escolar.

Dentre os gestores, ouvi cinco profissionais. Todos com atuação destacada no ensino agrícola, nos últimos trinta anos. Em relação aos operadores, todos pertencentes à Escola Agrícola Paulo Guerreiro Franco, de Vera Cruz, procurei ouvir os funcionários mais antigos, sem preocupação com categoria funcional. Ouvi quatro professores, três de formação especial c um de educação geral.

A reunião das representações de gestores e operadores torna evidente a distância entre as duas instâncias do pensamento e da ação educacionais: a dos órgãos centrais e a da unidade escolar. Ratifica a existência do profundo fosso entre o proposto e o executado. Entretanto, os depoimentos singulares 
unem-se em torno de elementos comuns constitutivos da ideologia dominante que não são questionados. Os valores e o ideário hegemônico da sociedade capitalista brasileira fundamenta e estabelece o elo de ligação de todos os discursos, concretizando a unidade na diversidade. Cabe ainda ressaltar que, nas diferentes vozes, acha-se presente a consciência dos problemas de modo razoavelmente claro, o mesmo não ocorrendo com relação às possíveis soluções.

No capítulo quarto, sintetizo as colocações dos três primeiros capítulos e tento responder às questões norteadoras da pesquisa mediante a utilização de categorias teóricas.

Sôbre a questão das especificidades do ensino agrícola, cabe ressaltar que o superdimensionamento dessas especificidades funciona como um componente ideológico que acaba por ocultar as dimensões que o aproximam e o tornam semelhante aos demais ramos do ensino, o que, ao final, não contribui para a solução de seus problemas. A especificidade colocada em destaque torna-se a capa sob a qual se ocultam interesses mais amplos de natureza econômca e mesmo interesses corporativistas. As diversas reformas c transformações resultaram em alguma modernização da rede sem a ocorrência de mudanças estruturais de vulto. Acompanhando a tendência modernizante conservadora da sociedade em geral, o ensino agrícola escreve uma trajetória que se pode intitular de "como fazer mudanças sem mudar", visto que os problemas fundamentais permanecem sem solução. Ao longo de cem anos de evolução, as questões referentes à relação entre disciplinas c educação geral c conhecimentos específicos, formação de professores, gestão do sistema c da unidade escolar, relação teoriaprática, modelo de organização c funcionamento, custeio e manutenção da escola, ainda constituem um desafio conceitual, metodológico e político.

No bojo da reorganização do ensino público paulista, o agrícola volta a "mudar de endereço", porém a decisão é tomada da mesma maneira que $\mathrm{cm}$ épocas e movimentos anteriores: com realce em suas especificidades e da incapacidade da 
Secretaria da Educação para tratar do assunto. Parece que os responsáveis pela política educacional se esquecem de que o problema maior nao consiste em responder qual o gestor ideal para tais escolas, mas, sim, buscar a identidade do ensino médio em geral e do agrícola em particular. O problema que se coloca não é de "lugar", mas de filosofia e política educacionais.

Não é em função de sua próprias especificidades, ou da tentativa de torná-lo semelhante à educação em geral, que os problemas do ensino agrícola se apresentam de forma crônica, mas em função de sua natureza histórica.

As marcas das contradições da sociedade geral se traduzem nas formas históricas de organização c funcionamento das escolas, pois estas são estruturadas na cotidianidade da prática social global. Uma sociedade dicotomizada na sua origem, cuja dicotomia se pereniza e se fortalece nos processos de modernização conservadora, reforça, aos invés de superar, as clássicas dicotomias educação geral $\mathrm{x}$ fomiação especial, teoria $\mathrm{x}$ prática $\mathrm{e}$ ensino x produção. Nesse sentido, a trajetória do ensino agrícola denota nas suas melhores formas apenas uma conciliação mecânica ou justaposição artificial dos opostos considerados, uma "dinâmica de caleidoscópio". Daí, a meu ver, o ensino agrícola tal como está estruturado nao realizar a superação de suas dicotomias aparentes. Isso fica subentendido, também, nos inúmeros diagnósticos levados a efeito pelos órgãos do sistema, como nas representações de seus atores ao revisitarem sua prática.

Contudo, cabe ressaltar que embora ausente do discurso sobre o ensino agrícola, a ligação quase intima com as questões da educação em geral brota no momento da identificação de seus problemas principais e das possíveis soluções. Assim identificam-se como cruciais os seguintes pontos:

1. A formação de professores, traduzida nas dificuldades de desenvolvimento curricular, em especial, no que se refere à relação teoria $\mathrm{x}$ prática.

2. O papel do Estado no custeio e manutenção dos serviços de ensino médio. 
3. A autonomia da unidade es- soluções para a perspectiva de um colar contraposta à burocratização ensino politécnico. do sistema, bem com à questão da 5 . As dificuldades conceituais e unidade escolar. metodológicas.

4. O impacto do avanço tecno6. A ausência de uma política e lógico nos processos produtivo e de uma filosofia educacionais educacional, encaminhando as claramente definidas. 